\title{
Kluyvera georgiana
}

National Cancer Institute

\section{Source}

National Cancer Institute. Kluyvera georgiana. NCI Thesaurus. Code C86464.

A species of facultatively anaerobic, Gram negative, rod shaped bacteria assigned to the phylum Proteobacteria. This species is motile by peritrichous flagella, catalase and indole positive, oxidase negative and does not ferment $\mathrm{D}$ sorbitol. K. georgiana is commonly isolated from human sputum and throat cultures and is an opportunistic pathogen. 